\title{
Social Support, Coping Strategies and Quality of Life in Attempted Suicide : A Hospital Based Study
}

\author{
Dr. Bhubaneswar Roy ${ }^{1}$, Dr. Priyajyoti Chakma ${ }^{2}$ \\ ${ }^{1}$ Assistant professor, Department of Psychiatry, Agartala Govt. Medical College, Agartala \\ Tripura West, 7990061 \\ ${ }^{2}$ Registrar, Department of Psychiatry, Agartala Govt. Medical College, Agartala \\ Tripura West, 7990062
}

\section{ABSTRACT}

Background : There is a major concern all over the world regarding the rise in attempting suicide in certain population especially among the young. Wide variations have been found in suicidal attempt among different cultures, societies and countries. The rate of attempted suicide is $8-10$ times more than the completedsuicide. Coping is most often conceptualized as a response to the demands of specific stressful situations. Though deliberate self-harm encompasses a wide variety of medical and social disciplines some of the important psychosocial variable such as social support, coping strategies, and quality of life has not yet been explored in depth in India.

Aims : The aim was to analyze and compare the coping strategies, social support, and quality of life of suicide attempters versus matched normal controls, and to identify the risk factors leading to suicide.

Settings and Design : The study was conducted in the Department of Psychiatry, Agartala Govt. Medical College \& GBP Hospital, Agartala, Tripura. The samples for the study were recruited from different outpatient \& indoor facilities of the GBP Hospital after application of the inclusion and exclusion criteria $(n=100)$ cases of suicide attempters and healthy controls $(n=100)$ were included in the study.

Materials and Methods : A total of 100 consecutive suicide attempters were compared with same number of age, sex, and marital status matched healthy controls using Social Support Questionnaire, Bengali version of ways of coping Quissionare (Susan Folkman and Richard S. Lazarus) and WHO QOL-Bref. Statistical analysis was done by using SPSS - 20,

Results : Attempters experienced significantly less Social support. Most common Coping strategies used by the suicide attempters were confronting coping $(72.5 \%)$ followed by distancing $(60 \%)$ and predominant coping strategies used by the control groups were seeking social support (60\%), accepting responsibility (52) and self-controlling (45\%). Positive coping, and of QOL were significantly lower in attempters. Among all risk factors good education and good social support were protective against suicide.

Conclusion : Suicide attempters were differentiated from healthy controls basedon lower social support, less healthy coping, and poor QOL. However, it is difficult to pinpoint a single factor responsible for suicidal behavior. It is the complex interplay of various interrelated factors and the resultant buffering effect, which is protecting the individual against deliberate self-harm.

Key words : Coping strategies, deliberate self-harm, quality of life, social support. 
Social Support, Coping Strategies, and Quality of life in Attempted Suicide : A Hospital Based Study

\section{Correspondence :}

Dr. Priyajyoti Chakma, Registrar, Department of Psychiatry, AGMC \& GBP Hospital, Agartala, 799006, Tripura, India. Phone no. - 8131043421, Email : pjchakma84@gmail.com

\section{INTRODUCTION}

The World Health Organization defines suicide act as "the injury with varying degrees of lethal intent and that suicide may be defined as a suicidal act with fatal outcome." Suicide worldwide was estimated to represent $1.8 \%$ of the total global burden of disease in 1998; in 2020, this figure is projected to be $2.4 \%$ in countries with market and former socialist economies.Deliberate self-harm is a major issue in the health care all over the world. ${ }^{1}$ Many factors including biological, socio-cultural, and personality traits can modify this complex behavior. Suicide is a significant problem in India also with a reported rate of 10.8 per 100,000 population. ${ }^{2}$ However it may be considerable underestimate due to underreporting and false reporting of many of the cases of suicides in India. ${ }^{3}$ Certain thought provoking studies on suicide have been reported from India. ${ }^{4}$ However, some of the important psychosocial variables such as life events or stressors, social support, coping strategies, and quality of life have not yet been assessed in relation to deliberate self-harm in India. Life change could act as a stressor causing physiological arousal and enhanced susceptibility for illness. Suicide victims have experienced more changes in living conditions, work problems, and object losses than normal controls. ${ }^{5}$

A body of research in recent years has focused on the role of social support in maintaining emotional well-being and moderating the effects of life events. There is evidence that Social network among suicide attempters are weaker than in non-suicidal individuals. ${ }^{6}$ Life events can alter the social support system in terms of size, frequency of interaction and stability, and such changes may be associated with suicidal behaviors.
Coping behavior, or the things people do to reduce the stress, has been a variable that has recently become the focus of research. ${ }^{7}$ Coping behavior is operationally defined as the responses to external life stress that serve to prevent, avoid, reduce or control stress and emotional distress.

Tripura tops suicide rate among small states in Northeastern region. The 2011 statistics from the National Crime Records Bureau (NCRB) reveal that $1,35,585$ people died of suicide in India, with Tripura topping the list with 703 reported cases, followed by Sikkim (184), Arunachal Pradesh (134), Mizoram (90), Nagaland (33), and Manipur (33).

Considering the paucity of such work from the Indian context the present study was conducted to analyze and compare the coping strategies and social support, and quality of life of suicide attempters and matched normal controls and to identify the risk factors leading to suicide attempt.

There is dearth of study on this subject of Social support, coping strategies, and quality of life in attempted suicidefrom North-Eastern part of the country as yet. Hence, the present study is a sincere effort in this direction

\section{MATERIALS AND METHODS}

Study Sample : The study was done in Agartala Govt. medical college \& GBP hospital which is tertiary care center situated in Agartala, Tripura.

The Design of the Study : The sample comprised 100 suicide attempters qualifying the criteria for suicide attempt as defined by WHOadmitted to different departments of AGMC \& GBP hospital. These patients were interviewed within the first week of their admission. Whereverpossible, relatives, friends, and other possible sources of information such as spouse and colleagues were also interviewed for eliciting further information. 
Socio demographic information was gathered as per prepared standard questionnaire. Ethical approval \& consent of the patients \& controls were obtained in the initial portion of the study. Age, sex, and marital statusmatched healthy controls from the community formed the comparison group. These subjects were initially screened by GHQ-12 version 10 to exclude the presence of common mental disorders. The period of the study was one year from January 2015 to December 2015.

The Aim of the Study : The aim was to analyze and compare the coping strategies, social support, and quality of life of suicide attempters versus matched normal controls, and to identify the risk factors leading to suicide.

Inclusion Criteria : a) Those patients \& control groups giving consent to participate in the study. b) Suicide attempters qualifying the criteria for suicide attempt as defined by $\mathrm{WHO}$ c) patients\& control groups who were above 18 years of aged) Patients of both sexes. e) Informants of both sexes. f) healthy control of both sexes

Exclusion Criteria :a) Mental Retardation.b) Patients below the age of 18 years c) chronic debilitating physical illness whose physical condition did not allow detailed evaluation.

Tools used were a) informed consent form, b) proforma for socio demographic data, c) ICD 10 Diagnostic guideline, d) Social support questionnaire : This scale was specially developed by poling items from Social Support Scale of Asha ${ }^{8}$ and the Social Support Scale of Nehra, Kulhara, and Verma9 by item analysis. Out of 47 items 22 were positively worded and 25 were negatively worded. The positive statements were intermingled with negative statements to reduce the likelihood of response set occurring. This scale has approximately the same number of items from each area. The retest reliability obtained for this scale was 0.89 .

e) Ways of coping questionnaire (WOCQ) : WOCQ (ways of coping questionnaire) was translated to local language (Assamese) WOCQ scales reliability
Alpha values for 8 subscales of WOCQ came 0.87, $0.76,0.91,0.88,0.95,0.89,0.77$, and 0.97 respectively which suggests the statistical reliability of the scale. Ways of coping questionnaire is primarily a research instrument in studies for assessment of coping process. It was developed by Susan Folkman and Richard S. Lazarus in 1980. The questionnaire is designed to identify the thoughts and action of an individual has used to cope with a specific stressful encounter.

The questionnaire measures total of 8 type of coping strategies namely Confronting coping, distancing, self-controlling, seeking social support, Accepting responsibility, escape avoidance, planful problem solving and positive reappraisal. There are total 66 questions in the full questionnaire. There are two methods of scoring the ways of coping questionnaire, raw and relative. The decision as to which set of score to use depends on the information desired. Raw score describe coping effort for each of the eight types of coping, whereas relative score describe the proportion of effort represented by each type of coping. In both methods of coping, individuals respond to each item on a 4-point. Likert used "1-indicates "used somewhat", 2- indicates "used quite a bit and 3- indicates "used a great deal". In the raw scoring the raw scores are the sum of the subjects responses to the items that comprises a given type of coping was used in a particular encounter. ${ }^{11-12}$

f) WHO QOL - Bref : WHO QOL-Brefcontains 26 items with four domains 1 . Physical health and well-being, 2. Psychological health and well-being, 3. Social relations, and 4. Environment. The scale has been shown to have good discriminant validity, sound content validity, and good test retest reliability at several international WHOQOL centers. ${ }^{13}$

Statistical Analysis : For comparison of quantitative variables we used a paired t-test or Wilcoxon signed rank test applied depending on whether the data were normally distributed or not. Quantitative variables were compared by a Mc-Nemar chi-square test. Statistical analysis was done by using SPSS-20. 
Social Support, Coping Strategies, and Quality of life in Attempted Suicide : A Hospital Based Study

\section{RESULTS}

Table 1 : Sample Characteristic

\begin{tabular}{|c|c|c|c|c|}
\hline \multirow[t]{2}{*}{ Variable } & \multicolumn{2}{|c|}{ Number = $100(\%)$} & \multirow[t]{2}{*}{$\mathrm{X} 2 / \mathrm{t}$} & \multirow[t]{2}{*}{ p value } \\
\hline & Attempters & Controls & & \\
\hline Mean age (years) & 29.52 & 30.12 & 1.8 & 0.06 \\
\hline SD & 12.85 & 13.42 & & \\
\hline \multicolumn{5}{|l|}{ Sex } \\
\hline Male & 56 & 56 & 0.08 & 0.92 \\
\hline Female & 44 & 44 & & \\
\hline \multicolumn{5}{|l|}{ Marital Status } \\
\hline Married & 30 & 30 & 3.12 & 0.74 \\
\hline Unmarried & 70 & 70 & 5.42 & $0.003^{* *}$ \\
\hline Mean education (years) & 10.02 & 12.20 & 7.43 & $0.002^{* *}$ \\
\hline SD & 3.87 & 3.76 & & \\
\hline \multicolumn{5}{|l|}{ Religion } \\
\hline Hindu & 75 & 73 & 8.32 & $0.001^{* *}$ \\
\hline Muslim & 15 & 15 & 6.42 & 0.56 \\
\hline Christian & 10 & 12 & 7.34 & 0.85 \\
\hline \multicolumn{5}{|l|}{ Domicile } \\
\hline Rural & 75 & 75 & 4.19 & 0.80 \\
\hline Urban & 25 & 25 & 3.78 & 0002 \\
\hline \multicolumn{5}{|l|}{ Occupation } \\
\hline Employed & 35 & 35 & 1.78 & 0.95 \\
\hline Unemployed & 65 & 65 & 2.42 & 0.001 \\
\hline Psychiatric illness in first degree relatives & 36 & 32 & 1.86 & 0.67 \\
\hline Past psychiatric illness & 19 & 00 & 2.85 & 0.96 \\
\hline Medical illness & 25 & 10 & 2.67 & 0.83 \\
\hline Past suicidal attempts & 15 & 00 & 3.84 & 0.001 \\
\hline
\end{tabular}

** $\mathrm{p}$ value $<0.05$ (Significant)

The sample comprised 100 suicide attempters and 100 controls matched on age, sex, and marital status. The mean age of attempters versus control was $29.52 \pm 12.85$ vs. $30.12 \pm 13.42$ and the male female ratio was male attempters $56(56 \%)$ vs. male control $56(56 \%)$ and female attempters $44(56 \%)$ vs. female control 44 (56\%). In both groups 30\% were married. Education, unmarried shows statistically significant. it signifies that less education and loneliness involved more suicidal attempt. In this study shows Hindu people are more prone to developed suicidal attempt (Table 1) 
Social Support, Coping Strategies, and Quality of life in Attempted Suicide : A Hospital Based Study

Table 2 : Psychiatric Disorder found in Sample (Attempted Suicide)

\begin{tabular}{|l|c|c|c|c|}
\hline \multicolumn{1}{|c|}{ Psychiatric Disorder } & ICD 10 & \multicolumn{2}{c|}{ N=52 } & Percentage \\
\hline & & Attempters & Controls & \\
\hline Mood disorders & F31 \& F32 & 16 & 00 & 30.76 \\
\hline Adjustment disorder & F43.2 & 24 & 00 & 46.15 \\
\hline Substance dependence & F10.2 \& F11.2 & 04 & 00 & 7.69 \\
\hline Schizophrenia & F20 & 03 & 00 & 5.76 \\
\hline Personality disorder & F60 & 02 & 00 & 3.84 \\
\hline Panic disorder & F41 & 01 & 00 & 1.92 \\
\hline Dissociative disorder & F44 & 02 & 00 & 3.84 \\
\hline
\end{tabular}

In this study it was found that the commonest comorbid psychiatric diagnosis was adjustment disorder with emotional disturbance $(46.15 \%)$. followed by $30.76 \%$ mood disorders, $7.69 \%$ substance dependence, 5.76\% schizophrenia, 3.84\% personality disorder, dissociative disorder \& $1.92 \%$ panic disorder. (Table 2)

Table 3 : Comparison of Variables in Social Support Scale

\begin{tabular}{|l|c|c|c|c|}
\hline \multicolumn{1}{|c|}{ Social Support } & \multicolumn{2}{c|}{ Mean SD } & t value & p value \\
\hline & Attempters & Controls & & \\
\hline Total score & $115.42 \pm 15.32$ & $120.23 \pm 13.23$ & 7.870 & $0.001^{* *}$ \\
\hline Reliable attachment & $34.42 \pm 5.74$ & $36.67 \pm 6.74$ & 5.240 & 0.84 \\
\hline Integration from friends & $30.26 \pm 9.70$ & $34.23 \pm 12.23$ & 5.023 & $0.002^{* *}$ \\
\hline Teachers/parental figures/elders & $17.78 \pm 3.67$ & $19.84 \pm 4.23$ & 2.982 & $0.001^{* *}$ \\
\hline Religion & $08.43 \pm 1.87$ & $10.30 \pm 2.45$ & 1.854 & 0.78 \\
\hline Other sources & $18.70 \pm 3.89$ & $15.67 \pm 2.76$ & 3.672 & $0.001^{* *}$ \\
\hline
\end{tabular}

${ }^{* *} \mathrm{p}<0.05$ significant

Comparison of social support variables between attempters \& controls showed significant lower

Table 4 : Comparison of Coping Behavior between Attempters \& Controls

\begin{tabular}{|l|c|c|c|c|c|c|}
\hline \multirow{2}{*}{ Coping Behavior } & \multicolumn{2}{|c|}{ Mean SD } & $\begin{array}{c}\text { Percentage } \\
\text { (attempters) }\end{array}$ & $\begin{array}{c}\text { Percentage } \\
\text { (controls) }\end{array}$ & $\mathbf{t}$ value & p value \\
\cline { 2 - 7 } & Atte mpters & Controls & & & \\
\hline Confronting coping & 30.20 & 29.56 & 72.5 & 32 & 2.897 & 0.89 \\
& 7.63 & 6.45 & & & & \\
\hline Distancing & 26.45 & 24.09 & 60 & 15 & 1.587 & 0.74 \\
& 5.22 & 4.24 & & & & \\
\hline Self-controlling & 19.60 & 22.76 & 15 & 25 & 3.434 & $0.002^{* *}$ \\
& 3.75 & 2.87 & & & & \\
\hline Seeking social support & 17.35 & 24.25 & 25 & 60 & 3.231 & $0.000^{* *}$ \\
& 1.89 & 2.02 & & & & \\
\hline Accepting responsibility & 18.20 & 19.80 & 22.5 & 52 & 2.765 & $0.001^{* *}$ \\
& 2.87 & 3.02 & & & & \\
\hline
\end{tabular}


Social Support, Coping Strategies, and Quality of life in Attempted Suicide : A Hospital Based Study

\begin{tabular}{|l|c|c|c|c|c|c|}
\hline \multirow{2}{*}{ Coping Behavior } & \multicolumn{2}{|c|}{ Mean SD } & Percentage & Percentage & \multirow{2}{*}{ t value } & p value \\
\cline { 2 - 7 } & Atte mpters & Controls & (Attempters) & (Controls) & & \\
\hline Escape avoidance & 13.34 & 12.74 & 30 & 10 & 1.672 & 0.94 \\
& 1.45 & 1.04 & & & & \\
\hline Planful problem solving & 13.78 & 16.78 & 17.5 & 45 & 1.234 & 0.85 \\
& 1.89 & 2.56 & & & & \\
\hline Positive reappraisal & 34.45 & 32.24 & $35 \mathrm{w}$ & 32 & 0.123 & 0.75 \\
& 5.45 & 5.89 & & & & \\
\hline
\end{tabular}

** $p$ value $<0.05$ Significant

Comparison of different types of coping behavior between attempters \& controls showed that scores for self-controlling, seeking social support \& accepting responsibility were significantly higher in controls. Most common Coping strategies used by the suicide attempters were confronting coping $(72.5 \%)$ followed by distancing (60\%), Positive reappraisal (35\%) and predominant coping strategies used by the control groups were seeking social support $(60 \%)$, accepting responsibility (52) and self-controlling (45\%). (Table 4)

Table 5 : Comparison of QOL between Attempters \& Controls

\begin{tabular}{|l|c|c|c|}
\hline \multirow{2}{*}{ QOL Variable } & \multicolumn{2}{|c|}{ Mean SD } & \multirow{2}{*}{ p value } \\
\cline { 2 - 3 } & Attempters & Controls & \multirow{2}{*}{$0.001^{* *}$} \\
\hline Physical health \& well being & 20.12 & 23.12 & \\
\hline Psychological health \& well being & 5.21 & 4.74 & $0.002^{* *}$ \\
& 20.08 & 22.42 & \\
\hline Social relations & 4.76 & 3.56 & $0.000^{* *}$ \\
\hline Environment & 10.24 & 12.76 & \\
\hline & 3.02 & 2.86 & $0.000^{* *}$ \\
\hline
\end{tabular}

${ }^{* *} \mathrm{p}$ value $<0.05$ (Significant)

The mean scores of all the four domains of QOL (physical health and well-being, psychological health and well-being, social relations and environment) were significantly lower in the attempters [Table 5].

\section{DISCUSSION}

The present study attempted to differentiate suicide attempters from healthy controls based on their profile of social support, coping strategies, psychiatric diagnosis, and quality of life. Attempters had accumulation of life events especially unpleasant and personal events, lower social support, poor coping styles, and poor quality of life. Life events and other psychosocial stressors are commonly associated with suicidal behavior when attempters were compared to the general population and nonsuicidal psychiatric patients Osvath et al. ${ }^{14}$ reported recent life events in $80 \%$ of suicides; job problems (28\%), family discord (23\%), somatic illness $(22 \%)$, financial problems $(18 \%)$, unemployment $(16 \%)$, separation $(14 \%)$, death $(13 \%)$, and illness in a family member. In the present study psychosocial stressors like financial loss ( $34 \%$ vs. $14 \%$ ), family 
conflict (30\% Vs 6\%), marital conflict (18\% Vs 05), broken engagement, and love failure $(12 \%$ vs. $2 \%$ ) and major personal illness ( $10 \%$ Vs $2 \%$ ) were significantly higher in attempters than controls.

Coping skills are important protective factors against suicide. In the present study healthy coping behaviors such as self-controlling, seeking social support \& accepting responsibility were significantly higher in controls.

Social support is another important protective factor againstsuicide. Social supportis provided bynetwork comprising family, relatives, friends, neighbors, and coworkers, especially when the interaction is positive. The personal networks may provide social support that helps to maintain emotional well-being and buffer the effect of adverse life events, or it can have a direct, independent effect on mental health irrespective of presence or absence of stressful life events. ${ }^{15}$ In the present study, confiding relationship, support from reliable attachment, friends, teachers, parental figures, elders, and other sources were significantly lower in attempters. There is evidence from comparative studies that social support systems are undermined among suicide attempters compared with non-suicidal individuals. ${ }^{16}$

Quality of life is an important variable in assessing the suicide risk. Since this is relatively a new area, only few studies have looked into this aspect in suicide attempters. ${ }^{17}$ The score on all the four domains namely physical health and well-being, psychological health and well-being, social relations and environment were significantly lower in attempters in this study. Dissatisfaction with life at baseline is reported as a risk factor for suicide.18Suicide was significantly associated with low quality of life in China. ${ }^{19}$

Western literature reports that about $90 \%$ of all those who attempt suicide suffer from a psychiatric disorder. ${ }^{20}$ In a series of studies from the Indian context, the predominant psychiatric problem was adjustment disorder closely followed by major depression and alcohol abuse/ dependence. ${ }^{21-22}$ Pondicherry (which has a high rate of alcohol consumption) also has the highest suicide rate in (58\%) in India. ${ }^{2}$ Good education, and good social support are protective factors against suicide.

\section{LIMITATIONS}

The main limitation of this study was a biased control group which was purposefully done to match the psycho-socio-demographic characteristics with the study group in order to reduce the confounding variables as much as possible. Other variables such as personality profile, proneness to violent behavior, and impulsivity should also be considered to differentiate suicidal individuals from controls.

\section{CONCLUSIONS}

This study concludes that Social support, positive coping behaviors, and QOL were significantly lower in attempters. However, it is difficult to pinpoint a single factor responsible for suicidal behavior.

\section{REFERENCES}

1. W.H.O. Prevention of suicide. Public Health Paper : No. 35. Geneva : World Health Organization; 1968.

2. National Crime Record Bureau. Accidental deaths and suicides in India. New Delhi, Ministry of Home Affairs : Govt. of India 2009.

3. Gajalakshmi V, Peto R. Suicide rates in rural Tamil Nadu, South India : Verbal autopsy of 39000 deaths in 1997-98. Int J Epidemiol 2007; 36 : 203-7.

4. Kumar PN. Analysis of suicide attempters versus completers-study from Kerala. Indian J Psychiatry 2004; 46 : $144-9$.

5. Hagnell O, Rorsman B. Suicide in the Lundby study : A controlled prospective investigation of stressful life events. Neuropsychobiology 1980; $6: 319-32$.

6. Hart EE, Williams CL, Davidson JA. Social behaviour, social networks and psychiatric diagnosis. Soc Psychiatr Psychiatr Epidemiol 1988; 23 : 222-8.

7. Lazarus RS. The Psychology of coping : Issues of research and assessment. In : Coehlo GV, Humburg DA, Adams JE, editors. Coping and adaptation. New York: Basic Books; 1974.

8. Asha CB. Social Support Scale, (Unpublished). University of Calicut, 1996. 
9. Nehra R, Kulhara P, Verma SK. Development of a scale for assessment of social support : Initial try out in Indian settings. Indian J Soc Psychiatry 1996; 3 : 353-9.

10. Goldberg D, Williams P. A user's guide to General Health Questionnaire, NFER - Nelson : Windsor 1998.

11. Lazarus RS, Folkman S. Stress, appraisal and coping 1984; 6 : 141-143.

12. Lazarus RS. Coping theory and research : past, present and future. Psychosomatic medicine 1993; 55 : 234-247.

13. Saxena S, Carlson D, Brillington R, Orley J. The WHO quality of life assessment instrument (WHOQOL-Bref) : The importance of its items for cross-cultural research. Quality of Life Research. Vol. 10. Netherlands: Kluwer Academic Publishers; 2001. p. 711-21.

14. Osvath P, Voros V, FeketeS. Lifeevents and psychopathology in a group of suicide attempters. Psychopathology 2004; 37 : 36-40.

15. Ponizovsky AM, Grinshpoon A, Levav I, Ritsner MS. Life satisfaction and suicide attempts among persons with schizophrenia. Comp Psychiatry 2003; 44 : 442-7.
16. Soykan A, Araplaslan B, Kumbasar H. Suicidal behaviour, satisfaction with life, and perceived social support in end stage renal disease. Transplantation Proc 2003; 35 : 1290-1.

17. Cui S, Yang R, He F, Zheng Y. Case-control analysis and follow up study on risk factors of suicide attempt in a rural population in Shandong Province. Wei Sheng Yan Jiu 2003; $32: 562-4$.

18. Koivumaa-Honkanen H, Honkanen R, Vinamakai K, Kaipro J, Koskenvuo M. Life satisfaction and suicide : a 20-year follow-up study. Am J Psychiatry 2001; 158 : 433-9.

19. Phillips MR, Yang G, Zhang Y, Wang L, Ji H, Zhou M. Risk factors for suicide in China : A national case-control psychological autopsy study. Lancet 2002; 360 : 1728-36.

20. Zonda T. One-hundeed cases of suicide in Budapest-Acase controlled Psychological autopsy studty. Crisis 2006; 27 : 125-9.

21 Vijayakumar L, Rajkumar S. Are risk factors for suicide universal? A case-control study in India.ActaPsychiatrScand 1999; 99 : 407-41.

22. Kumar PN. An analysis suicide attempters versus completers in Kerala. Ind J Psychiat 2004; 46 : 144-9. 